\title{
A cell-microelectronic sensing technique for the screening of cytoprotective compounds
}

\author{
BÉLA ÓZSVÁRI ${ }^{1}$, LÁSZLÓ G. PUSKÁS ${ }^{1,2}$, LAJOS I. NAGY ${ }^{1}$, IVÁN KANIZSAI ${ }^{1}$, MÁRIÓ GYURIS ${ }^{1}$, \\ RAMÓNA MADÁCSI ${ }^{1}$, LILIÁNA Z. FEHÉR ${ }^{1}$, DOMOKOS GERÖ ${ }^{3}$ and CSABA SZABÓ 3,4 \\ ${ }^{1}$ Avidin Ltd. Szeged, Közép Fasor 52; ${ }^{2}$ Laboratory for Functional Genomics, Department of Genetics, \\ Biological Research Center, HAS, H-6726 Szeged; ${ }^{3}$ CellScreen Applied Research Center, \\ Semmelweis University Medical School, H-1091 Budapest, Hungary; ${ }^{4}$ Department of Anesthesiology, \\ University of Texas Medical Branch, Galveston, TX 77555, USA
}

Received November 30, 2009; Accepted January 15, 2010

DOI: 10.3892/ijmm_00000373

\begin{abstract}
In recent years, a new cell-based high throughput paradigm has emerged, which seeks to identify novel, pharmacologically active cytoprotective compounds. The essence of this approach is to create experimental models of cell injury relevant for a particular disease by establishing in vitro cellbased models, followed by high-throughput testing of compounds that affect the cellular response in a desired manner. Prior approaches typically used simple end-point analyses. To assess the cytoprotective effects of novel drug candidates in real-time, we have applied a cell-microelectronic sensing technique (RT-CES), which measures changes in the impedance of individual microelectronic wells that correlates linearly with cell index (reflecting cell number, adherence and cell growth), thereby allowing the continuous determination of cell viability during oxidative stress. In vitro cytotoxicity was elicited by hydrogen peroxide in myocytes (H9c2) and hepatocytes (Hep3B). Cells were post-treated at $30 \mathrm{~min}$ with various reference molecules and novel cytoprotective compounds. Cytoprotection detected in the RT-CES system correlated well with the results of two classical end-pointbased methods (improvement in MTT and reduction of LDH release). The RT-CES method, when used as described in the current report, is suitable for the screening of molecular libraries to identify molecules or molecule combinations that attenuate oxidative stress-induced cell damage.
\end{abstract}

\section{Introduction}

Oxidative stress is an important contributing factor to the progression of various cardiovascular and neurological diseases including myocardial infarction, hypertension, cerebral ischemia, hypoxia, as well as to the progression of age-related

Correspondence to: Dr László G. Puskás, Avidin Ltd., Szeged, Közép Fasor 52, H-6726, Hungary

E-mail: laszlo@avidinbiotech.com

Key words: cytoprotection, oxidative stress, cell electronic sensing neurodegenerative disorders such as Alzheimer's disease and Huntington's $(1,2)$. Multiple groups of investigators, working at pharmaceutical companies or academic laboratories have conducted many studies aimed at the identification of cytoprotective drugs, in order to protect various vital organs from irreversible oxidative injuries (3-9). The identification of such molecules generally involves a high-throughput screening of molecular libraries. Potential cytoprotective drug candidates emerging from such screening can be further tested in vivo.

Current in vitro methods to investigate cytotoxic or cytoprotective effects of molecules in cells exposed to oxidative stress usually involve labeled tracers for the detection of cellular functions. Classic detection techniques include fluorescence and luminescence assays, radioisotope-based methods or optical absorbance measurements, which usually require a labeled ligand, an enzyme substrate or a tracer molecule (3-9). These methods can be costly, time-consuming, and rather complex due to washing steps, interference of detection by certain compounds, and potential interference with physiological conditions by the labeled molecule.

In recent years, new technological approaches have emerged enabling label-free detection methods for cell-based assays. One of the most sophisticated new techniques is the real-time cell electronic sensing technology, based on a special microelectronic sensor-based platform. This real-time electronic sensing system (RT-CES) provides a label-free detection of cell viability status in a simple homogeneous assay format, noninvasive measurement, reduced interference with normal cell function, kinetic measurement, and reduced time for assay development $(10,11)$. Here we apply this method to enable the screening for cytoprotective compounds in realtime. This screening enables the investigator to detect cell viability in a real-time fashion and with high sensitivity, while providing a noninvasive cellular environment during the measurement over a broad time frame (minutes to several days).

\section{Materials and methods}

Cell culture media and fetal bovine serum were purchased from Invitrogen (Carlsbad, CA, USA). Penicillin was obtained from Biogal Inc. (Debrecen, Hungary), streptomycin, hydrogen 
peroxide and gelatin solution was from Sigma-Aldrich (Hungary).

Cell lines and culture conditions. $\mathrm{H} 9 \mathrm{c} 2$ rat embryonal cardiac muscle cells (from ATCC, Rockville, MD, USA) were cultured in Dulbecco's Modified Eagle's Medium, containing 10\% fetal bovine serum, $4 \mathrm{mM}$ L-glutamine (Sigma-Aldrich, Hungary), $100 \mathrm{U} / \mathrm{ml}$ penicillin and $100 \mu \mathrm{g} / \mathrm{ml}$ streptomycin. Hep3B human hepatoma cells (from ATCC, Rockville, MD, USA) were cultured in Dulbecco's Modified Eagle's Medium, containing $10 \%$ fetal bovine serum, $100 \mathrm{U} / \mathrm{ml}$ penicillin and $100 \mu \mathrm{g} / \mathrm{ml}$ streptomycin. Each cell type was maintained in $100 \mathrm{~mm}$ TC dishes (Orange Scientific, Belgium) in an incubator with humidified air at $37^{\circ} \mathrm{C}$ and $5 \% \mathrm{CO}_{2}$. Primary co-culture of cerebral neuron and astrocyte cells was prepared according to Griffin S and colleagues (12). Cell cultures were kept in Eagle's Minimum Essential Medium, 10\% fetal bovine serum and 1\% non-essential amino acid solution (Sigma-Aldrich).

Real-time cell electronic sensing (RT-CES) cytoprotection assay. RT-CES 96-well E-plate (Roche, Hungary) was coated with gelatin solution $\left(0.2 \%\right.$ in PBS) for 20 min at $37^{\circ} \mathrm{C}$, then gelatin was washed twice with PBS solution. Growth media (80 $\mu 1$ ) (respective to cell types) were then gently dispensed into each well of the 96-well E-plate for background readings by the RT-CES system prior to addition of $80 \mu 1$ of cell suspension at a density of $10^{4}$ cells/well. Devices containing the cell suspension were kept at room temperature in a tissue culture hood for $30 \mathrm{~min}$ prior to insertion into the RT-CES device in the incubator to allow cells to settle. Cell growth was monitored overnight by measurements of electrical impedance every $5 \mathrm{~min}$. Continuous recording of impedance in cells was reflected by cell index value (13). Next day, the medium was changed and cells were post-treated (30 min after $\mathrm{H}_{2} \mathrm{O}_{2}$ treatment, respectively) with reference compounds as well as with test compounds (novel compounds with cytoprotective properties). Reference chemicals were the poly(ADP-ribose) polymerase (PARP) inhibitor PJ34 $(10 \mu \mathrm{M})(14)$, the cytoprotective NMDA antagonist MK-801 $(5 \mu \mathrm{M})$ and the calcium channel blocker verapamil $(20 \mu \mathrm{M})$. The novel cytoprotective drug candidates were (a) 9790, a fatty acid derivative $(5 \mu \mathrm{M})$ and (b) several hydroxyquinoline derivatives (molecules with Q code; 0.5-1 $\mu \mathrm{M}$ ), all synthesized by Avidin Ltd. The $\mathrm{H}_{2} \mathrm{O}_{2}$ concentration to elicit cell injury was optimized for the various cell types according to their sensitivity to oxidative stress as follows, $100 \mu \mathrm{M}$ for $\mathrm{H} 9 \mathrm{c} 2$ rat embryonal cardiac muscle cells and $250 \mu \mathrm{M}$ for Hep3B cells. Cells exposed to $\mathrm{H}_{2} \mathrm{O}_{2}$ and post-treated with the various test compounds were dynamically monitored over $24 \mathrm{~h}$ by measurements of electrical impedance every $5 \mathrm{~min}$. The raw plate reads for each titration point were normalized relative to the cell index status right before addition of $\mathrm{H}_{2} \mathrm{O}_{2}$. Each treatment was repeated in at least 2 wells per plate during the experiments.

MTT cell viability assay. The assay was performed as previously described (6). To estimate the number of viable cells 3-(4,5-Dimethyl-2-thiazolyl)-2,5-diphenyl-2H-tetrazolium bromide (MTT, Serva) was added to the cells at a final concentration of $0.5 \mathrm{mg} / \mathrm{ml}$ and cultured at $37^{\circ} \mathrm{C}$ for $1 \mathrm{~h}$. Cells were washed with PBS and the formazan dye was dissolved in

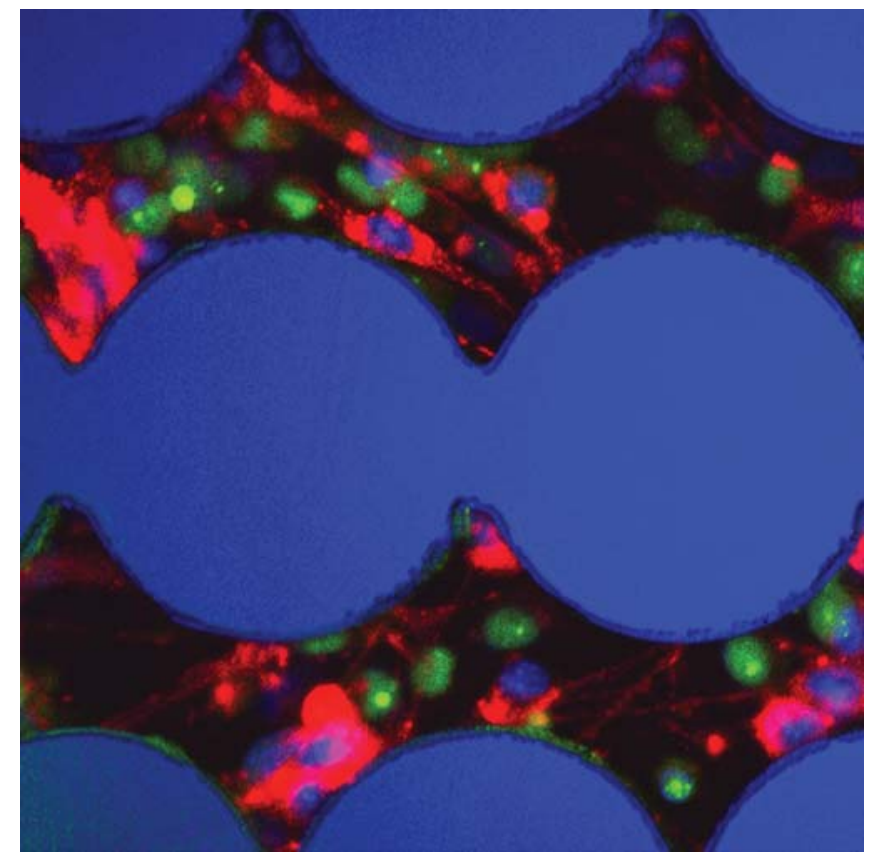

Figure 1. Multicolor fluorescent image of rat primary neuronal culture grown in a 96-well E-plate. Dark blue areas cover the gold microelectrodes at the bottom of a well. Before DAPI staining of the culture, cells were previously stained either with red or green fluorescent dyes to yield a more colorful image.

isopropanol. The amount of converted formazan dye was measured at $570 \mathrm{~nm}$ with background measurement at $690 \mathrm{~nm}$ on a Powerwave reader (Biotek, Winooski, VT). A calibration curve was created by measuring the MTT converting capacity of serial dilutions of cells, and viable cell count was calculated using Gen5 data reduction software. Measurements were performed at 3 and $24 \mathrm{~h}$ after $\mathrm{H}_{2} \mathrm{O}_{2}$ exposure in separate series of experiments.

LDH cytotoxicity assay. The assay was performed as previously described (6). Cell culture supernatant $(30 \mu \mathrm{l})$ was mixed with $100 \mu 1$ freshly prepared LDH assay reagent to reach final concentrations of $85 \mathrm{mM}$ lactic acid, 1,040 mM nicotinamide adenine dinucleotide $\left(\mathrm{NAD}^{+}\right), 224 \mathrm{mM}$ N-Methylphenazonium methyl sulfate (PMS), 528 mM 2-(4-Iodophenyl)-3-(4nitrophenyl)-5-phenyl-2H-tetrazolium chloride (INT) and $200 \mathrm{mM}$ Tris ( $\mathrm{pH} 8.2$ ). The changes in absorbance were read kinetically at $492 \mathrm{~nm}$ for $15 \mathrm{~min}$ on a monochromator-based reader (Powerwave HT, Biotek). LDH activity is expressed as $\mathrm{Vmax}$ in $\mathrm{mOD} / \mathrm{min}$. Supernatant was sampled at 3 and $24 \mathrm{~h}$ after $\mathrm{H}_{2} \mathrm{O}_{2}$ exposure and LDH activity was measured.

\section{Results}

Continuous determination of cell viability during oxidative stress by the RT-CES system on $H 9 c 2$ cells. In the first experiment $\mathrm{H} 9 \mathrm{c} 2$ rat embryonic cardiac muscle cells were cultured in a gelatin pre-treated 96-well E-plate and cell index was registered every $5 \mathrm{~min}$ with the RT-CES system during cell growth and was set to measure data before addition of $\mathrm{H}_{2} \mathrm{O}_{2}$. Cells were attached to the bottom of the wells as indicated by the rapid increase of the lines (Fig. 1) and were grown for $24 \mathrm{~h}$. Over this time, cell index was continuously 

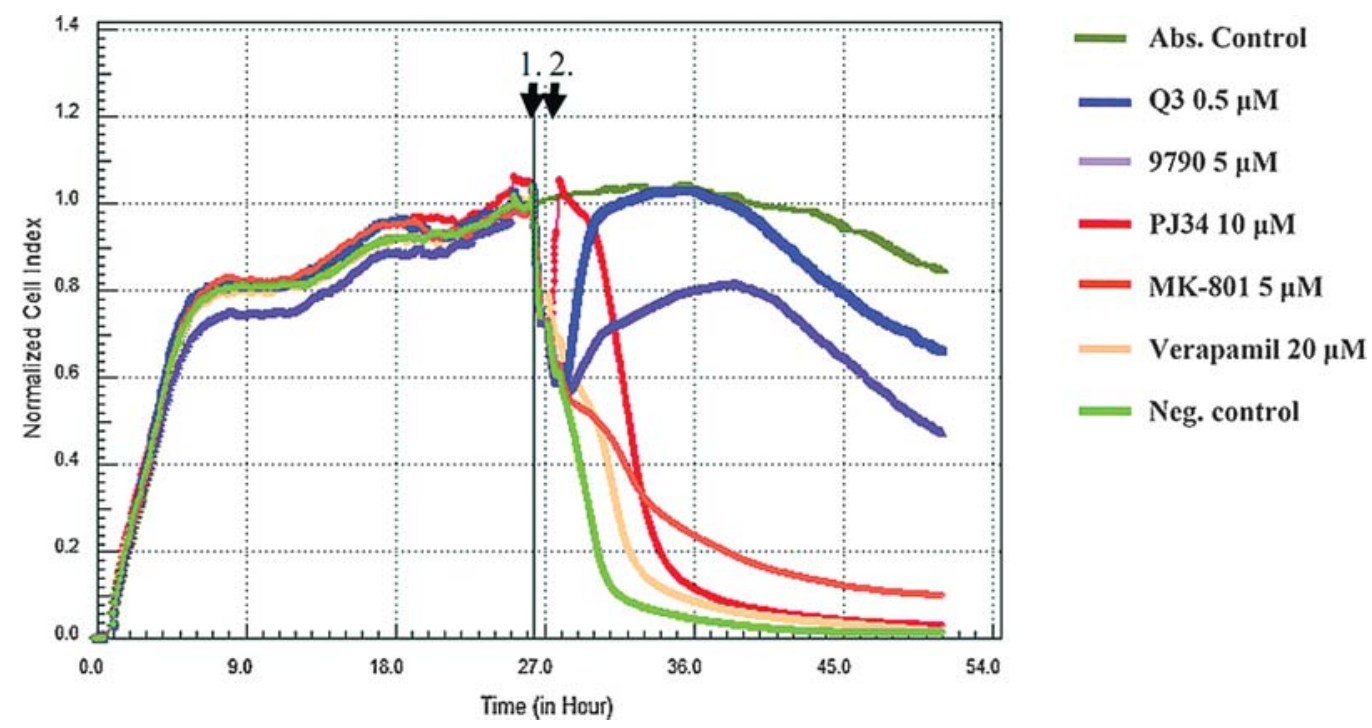

Figure 2. Determination of the effects of various test compounds on the cell index, measured by RT-CES method in cultured rat cardiomyocytes. H9c2 rat embryonal cardiac muscle cells were cultured in a gelatin pre-treated 96-well E-plate. Cells were attached and grown overnight and subjected to oxidative stress (100 $\mu \mathrm{M} \mathrm{H}_{2} \mathrm{O}_{2}$; arrow 1). After 30 min, test compounds (Q3, 9790) were added to the wells (arrow 2). Positive controls were PJ34, MK-801 and verapamil. Curves in the figure are measurements of single wells. Normalized cell index shows the relative viability of cells per well. The black vertical line in the middle of the graph indicates time of normalization of cell index, which is the time of $\mathrm{H}_{2} \mathrm{O}_{2}$ application.

increasing as a function of cell proliferation, maturation and increased confluence. The cytotoxic insult was elicited by the addition of $\mathrm{H}_{2} \mathrm{O}_{2}$ to cells (Fig. 2, arrow 1). Consistent with the fact that cardiac myocytes have greater vulnerability to oxidative stress compared with other cell types (15), exposure to $100 \mu \mathrm{M} \mathrm{H}_{2} \mathrm{O}_{2}$ already resulted in a rapid decrease of the cell index. We optimized the concentration of $\mathrm{H}_{2} \mathrm{O}_{2}$ to decrease the actual cell index by $25 \%$, so that the index of negative controls (untreated wells) would be zero after $\sim 3-4 \mathrm{~h}$ of the insult.

Compounds were applied in a 30-min post-treatment protocol after hydrogen peroxide. Previous studies demonstrated that transient oxidative stress (even for $5 \mathrm{~min}$ at $400 \mu \mathrm{M}$ ) triggers an intrinsic program leading to self-sustained apoptosis in $\mathrm{H} 9 \mathrm{c} 2$ cells via the secondary production of reactive oxygen species (ROS) and subsequent, delayed activation of the mitochondrial death pathway (16). We hypothesized that $30 \mathrm{~min}$ of untreated injury is sufficient to trigger the main effector pathways of cell death. Delayed treatment with test compounds would therefore be expected to identify molecules that do not merely prevent the onset of cell dysfunction, but, rather arrest it or activate pathways of cellular recovery. Compounds capable of such delayed cytoprotective effects would be expected to be more valuable than compounds that are only effective in the prolonged pretreatment protocols. In the current experiments, after $30 \mathrm{~min}$, various cytoprotective compounds (Q3 and 9790) were added to wells (Fig. 2, arrow 2). Positive controls were PJ34, MK-801 and verapamil. PJ34 is a PARP inhibitor $(14,17)$, which has a well-established function as a cardioprotective agent in vitro and in vivo $(18,19)$. Cell index of the absolute control cells that did not receive $\mathrm{H}_{2} \mathrm{O}_{2}$ treatment remained constant for $\sim 20 \mathrm{~h}$, but began to decline thereafter, probably due to the overgrowth of culture in the well. Vehicle-control cells (which received $\mathrm{H}_{2} \mathrm{O}_{2}$ and vehicle, but no treatment with cytoprotective compounds), showed a rapid decline of cell index, presumably as a consequence of cell shrinkage after oxidative stress (20) that is detected by the real-time cell microelectronic sensing system. At later time points, inhibition of cell viability, proliferation and death are also likely to contribute to the decline in cell index. The latter response is evidenced by the release of LDH into the culture medium (Fig. 4). Posttreatment of ischemic cardiac cells with PJ34 $(10 \mu \mathrm{M})$ resulted in a maintenance of the cell index for $3 \mathrm{~h}$, followed by a decline by $24 \mathrm{~h}$. MK-801, a non-competitive antagonist of the $\mathrm{N}$-methyl-D-aspartate (NMDA) receptor, exerts partial protection against $\mathrm{H}_{2} \mathrm{O}_{2}$ toxicity in cardiomyocytes (21). In our experiment, MK-801 $(5 \mu \mathrm{M})$ slightly protected against the loss of cell viability of $\mathrm{H} 9 \mathrm{c} 2$ cells during the first few hours and delayed the progressive decline of cell index over the next $24 \mathrm{~h}$ compared to vehicle control. The third positive control agent was verapamil, an L-type calcium channel inhibitor and a widely used anti-arrhythmic agent. This agent, which was included in our testing because of the known role of cellular calcium overload in myocyte death $(22,23)$ provided only a slight cytoprotective effect. Post-treatment of cells with the fatty acid derivative 9790 at $5 \mu \mathrm{M}$ prevented cells from the toxic effects of oxidative stress. Q3 at concentrations as low as $0.5 \mu \mathrm{M}$ maintained the cell index near absolute control levels for the initial $3 \mathrm{~h}$ of the experiments. Cell index remained markedly elevated high during the course of the entire experiment (Fig. 2).

We strongly recommend to avoid placing the E-plate on the cold surface of the cell culture hood as we experienced that cell index usually decreased with $5-10 \%$ even after media change (data not shown). The bottom of an E-plate is covered with electrode arrays made of metal, so E-plate promotes heat conductance and changes faster than standard plastic plates. This phenomenon was probably due to cold stress, that was found in previous studies to trigger cell adaptive response and enhance intracellular generation of ROS, including $\mathrm{H}_{2} \mathrm{O}_{2}$ (24). 

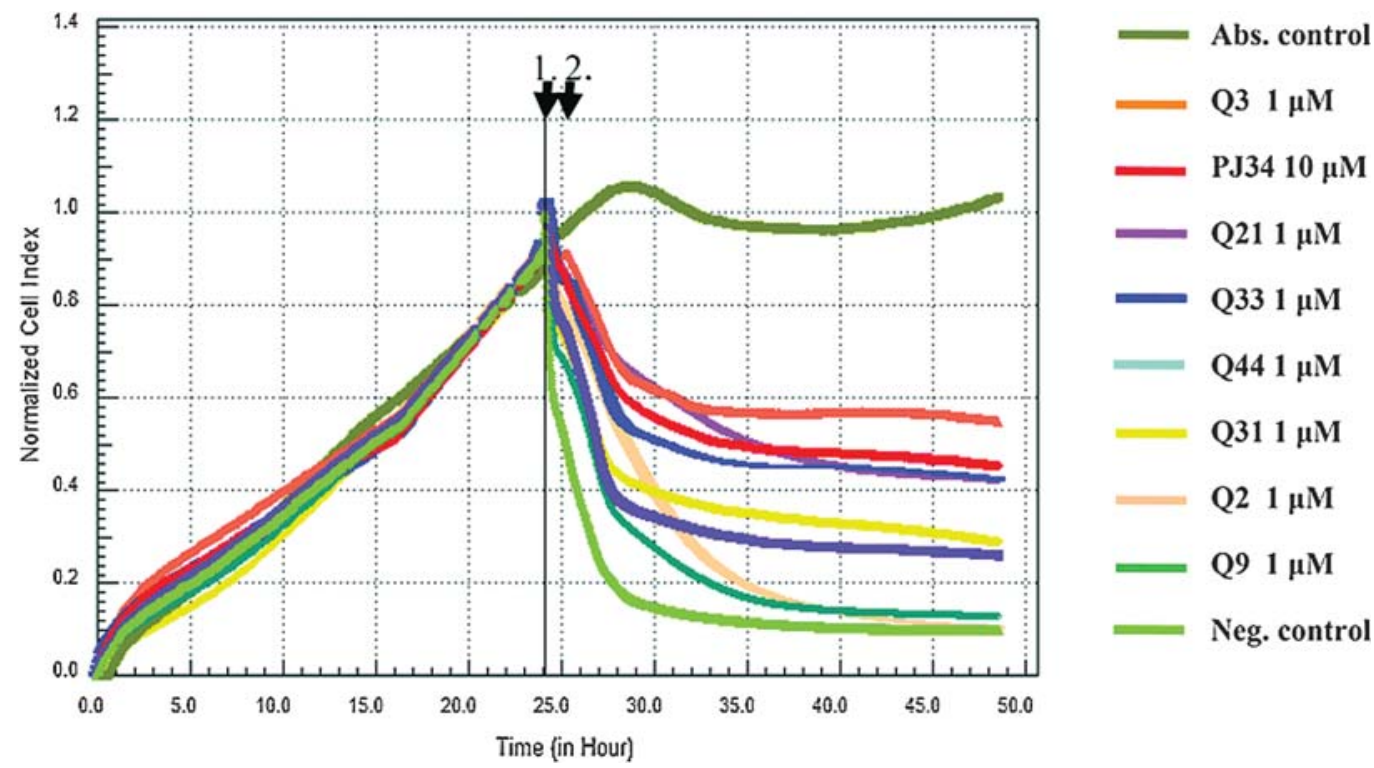

Figure 3. Determination of the effects of various test compounds on the cell index, measured by RT-CES method in cultured Hep3B human hepatoma cells. Hep3B cells were cultured in a gelatin pre-treated 96-well E-plate and were grown overnight. Arrow 1 shows the start of hydrogen peroxide application $(250 \mu \mathrm{M})$. After $30 \mathrm{~min}$, compounds from the Q series were applied (arrow 2). PJ34 was used as a positive control. Normalization of cell index was calculated at the time point of start of $\mathrm{H}_{2} \mathrm{O}_{2}$ application.

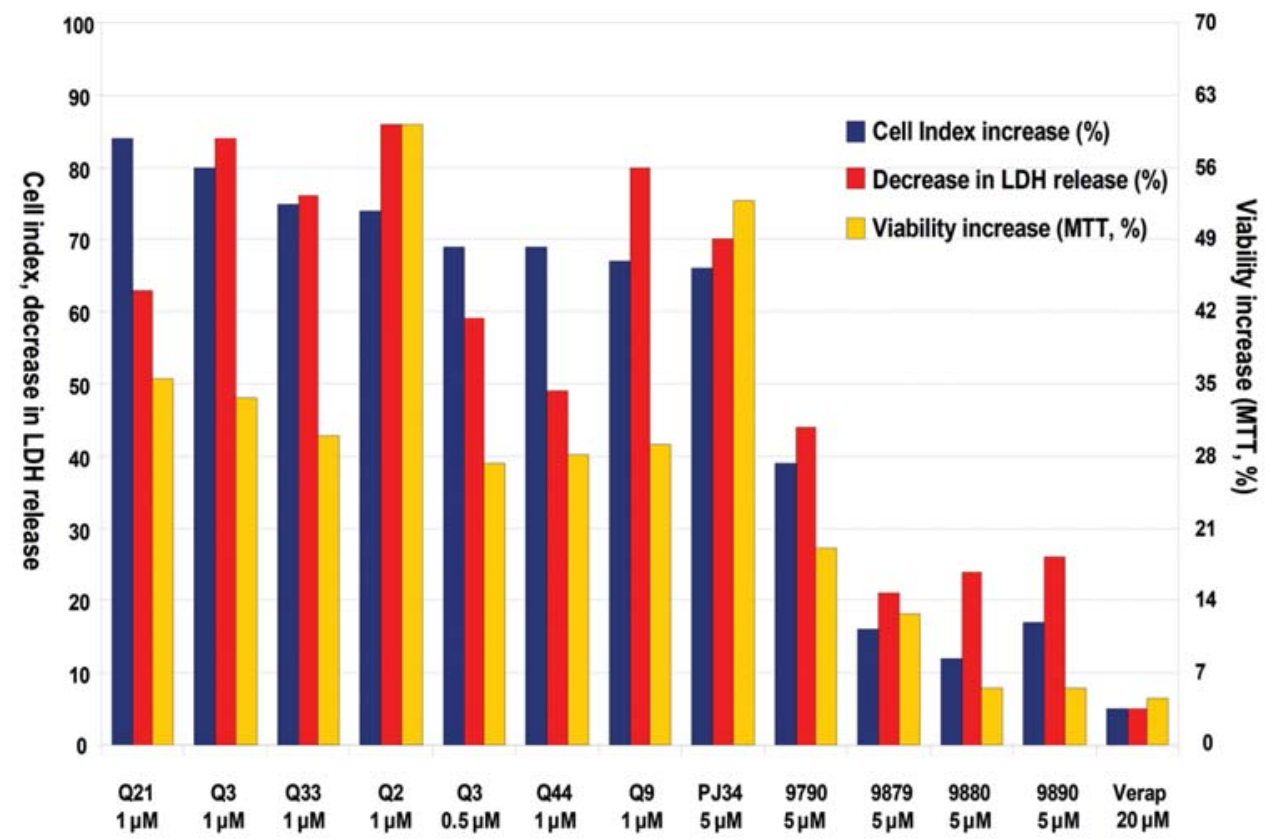

Figure 4. Comparison of cytoprotective effects measured by the RT-CES system, MTT assay and LDH release. H9c2 cells exposed to $\mathrm{H}_{2} \mathrm{O}_{2}$ were treated with test compounds at the indicated concentrations $30 \mathrm{~min}$ later. All data were calculated after $3 \mathrm{~h}$ of post-treatment. Cell index data were normalized to negative control, which was considered zero, absolute control data (without $\mathrm{H}_{2} \mathrm{O}_{2}$ treatment) were calculated as $100 \%$ increase. LDH activity was measured in the supernatant collected $3 \mathrm{~h}$ later. Please note that scale of MTT viability increase is displayed on the right side of the diagram. Data represent mean values of three determinations.

When we placed the E-plate on a metal block, preheated to $37^{\circ} \mathrm{C}$, the shift did not occur.

Screening of candidates of a molecule library for cytoprotection on Hep3B cells. In the next experiment we tested several Q compounds (Q2, Q3, Q9, Q21, Q31, Q33 and Q44) to assess their cytoprotective effects on Hep3B human hepatoma cells after 30 min of $\mathrm{H}_{2} \mathrm{O}_{2}$ treatment. In these cells a higher concentration of hydrogen peroxide $(250 \mu \mathrm{M})$ was used, consistent with the higher oxidant stress resistance of this hepatocyte line, as compared to the cardiac cell line used. Cell growth was linear until the application of hydrogen peroxide (Fig. 3). Post-treatment (30 min) with various compounds from the Q series markedly altered the slope of the cell index 
curves, thereby differentiating between the various compounds providing various degrees of cytoprotection. This experiment further demonstrates that RT-CES real-time measurement platform is an enabling tool for profiling the cytoprotective effect of compounds in a real-time measurement after $\mathrm{H}_{2} \mathrm{O}_{2}$ triggered oxidative stress.

Comparison of cytoprotective effects measured by the cellmicroelectronic sensing technique to standard cell viability assays. In H9c2 cells, we have also performed a series of parallel studies measuring LDH release and mitochondrial respiration (using the MTT assay) after $\mathrm{H}_{2} \mathrm{O}_{2}$ exposure, in the presence or absence of the same selection of compounds that were tested using the RT-CES assay. The degree of cytoprotection (Fig. 4) showed a good correlation between the MTT and the LDH assay, as expected from previous studies screening the potential cytoprotective effects of compounds from the LOPAC library (6). Importantly, the rank-order of the cytoprotective effects of the various compounds, as determined from the MTT and LDH assays was identical to the rank-order of the protection seen with the RT-CES method, verapamil provided no protection; the compound 9790 as well as PJ34 provided significant protection, and the Q series of compounds provided protective effects that had a comparable rank-order as seen in the RT-CES screen (Fig. 4).

\section{Discussion}

Recently, drug discovery assays have been developed that are more physiologically relevant and are aimed at a more reliable and faster screening. Label-free cell-based assays are often preferred as they tend to generate fewer false positive results and reduce nonspecific effects that may occur in the labelbased assays. In this study, the RT-CES system was used as a sensing technique for measuring cytoprotection of different compounds based on changes in cell index. This change in cell index after the $\mathrm{H}_{2} \mathrm{O}_{2}$ challenge is the result of changes in several factors related to cell viability, including changes in cell proliferation, cell morphology, and/or cell detachment from the microelectrodes due to cell death.

The xCELLigence System (co-developed by Roche and ACEA Biosciences) monitors cellular events in real-time without the incorporation of labels. It is based on proprietary microelectronic cell sensor arrays that are integrated in the bottom of the microtiter plates (96-well E-plate). When cells are cultured in a well, impedance is measured between sensor electrodes and the attached cells that act as insulators, leading to an increase in impedance. The relative electrical changes during a measurement are displayed by xCELLigence software as a unitless parameter termed Cell Index, which is calculated as a relative change in actual impedance divided by a previously registered background value. Thus, real-time measurement of cell index can give information on the actual cell viability status, and has been used in a number of cell morphology, adhesion, cell proliferation and receptor activity studies $(11,25-27)$.

We have set up a real-time cytoprotection assay based on the cell-microelectronic sensing technique and verified its results with standard cell viability assays. We propose that molecular libraries can be readily screened with this micro- electronic system in a high-throughput manner, in order to save time and expense. The resulting data are biologically relevant, because the elimination of labels brings the cells closer to physiological conditions. The microelectronic readout of the system is noninvasive and can be continuously monitored, and the kinetic profile of the experiment gives additional information about the state of the cells, with a time-resolution that cannot be achieved by standard endpoint assays. In the current report, we show the results of studies in two different cell lines. We have also conducted studies using this methodology in rat primary neuronal cells, and have made similar observations (data not shown). The present conclusions are also strengthened by recent data from an independent laboratory using keratinocytes and fibroblast cells on a cell proliferation monitoring model (28). In the light of increased demands for in vitro testing of cytoprotective drugs, the current method offers a novel cell-based high throughput approach for the effective and reliable screening of molecular libraries in order to screen for potential drug candidates for the experimental therapy of various diseases where the pathophysiology involves reactive species generation and associated cell injury.

\section{Acknowledgements}

We would like to thank Dr Jozsef Repasi (Ubichem Research Ltd.) for synthesis of fatty acid derivatives and Ferhan Ayaydin from the Cellular Imaging Laboratory, BRC-HAS, Szeged, Hungary for the fluorescent images and Noemi Nagy (Roche, Hungary) for her support and useful advice. This work was supported by grants from the Ányos Jedlik 'Avinomid', the National Technology Program 'Glinolid' and the Asboth Oszkar Program (National Research and Technology Office, Hungary).

\section{References}

1. Giordano FJ: Oxygen, oxidative stress, hypoxia, and heart failure. J Clin Invest 115: 500-508, 2005.

2. Butterfield DA, Howard BJ and LaFontaine MA: Brain oxidative stress in animal models of accelerated aging and the age-related neurodegenerative disorders, Alzheimer's disease and Huntington's disease. Curr Med Chem 8: 815-828, 2001.

3. Degterev A, Huang T, Boyce M, et al: Chemical inhibitor of nonapoptotic cell death with therapeutic potential for ischemic brain injury. Nat Chem Biol 1: 112-119, 2005.

4. Wang L, Gao X, Gao P, et al: Cell-based screening and validation of human novel genes associated with cell viability. J Biomol Screen 11: 369-376, 2006.

5. Mawji IA, Simpson CD, Gronda M, et al: A chemical screen identifies anisomycin as an anoikis sensitizer that functions by decreasing FLIP protein synthesis. Cancer Res 67: 8307-8315, 2007.

6. Gerö D, Módis K, Nagy N, Szoleczky P, Tóth ZD, Dormán G and Szabó C: Oxidant-induced cardiomyocyte injury: identification of the cytoprotective effect of a dopamine 1 receptor agonist using a cell-based high-throughput assay. Int J Mol Med 20: 749-761, 2007.

7. Huang R, Southall N, Cho MH, Xia M, Inglese J and Austin CP: Characterization of diversity in toxicity mechanism using in vitro cytotoxicity assays in quantitative high throughput screening. Chem Res Toxicol 21: 659-667, 2008.

8. Qiu BY, Turner N, Li YY, et al: A high-throughput assay for modulators of mitochondrial membrane potential identifies a novel compound with beneficial effects on $\mathrm{db} / \mathrm{db}$ mice. Diabetes (In press).

9. Iljin K, Ketola K, Vainio P, et al: High-throughput cell-based screening of 4910 known drugs and drug-like small molecules identifies disulfiram as an inhibitor of prostate cancer cell growth. Clin Cancer Res 15: 6070-6078, 2009. 
10. Solly K, Wang X, Xu X, Strulovici B and Zheng W: Application of real-time cell electronic sensing (RT-CES) technology to cell-based assays. Assay Drug Dev Technol 2: 363-372, 2004.

11. Boyd JM, Huang L, Xie L, Moe B, Gabos S and Li XF: A cellmicroelectronic sensing technique for profiling cytotoxicity of chemicals. Anal Chim Acta 615: 80-87, 2008.

12. Griffin S, Clark JB and Canevari L: Astrocyte-neurone communication following oxygen-glucose deprivation. J Neurochem 95: 1015-1022, 2005.

13. Xing JZ, Zhu L, Jackson JA, Gabos S, Sun XJ, Wang XB and $\mathrm{Xu}$ X: Dynamic monitoring of cytotoxicity on microelectronic sensors. Chem Res Toxicol 18: 154-161, 2005.

14. Jagtap P, Soriano FG, Virág L, et al: Novel phenanthridinone inhibitors of poly (adenosine 5'-diphosphate-ribose) synthetase: potent cytoprotective and antishock agents. Crit Care Med 30: 1071-1082, 2002.

15. Zhang X, Azhar G, Nagano K and Wie JY: Differential vulnerability to oxidative stress in rat cardiac myocytes versus fibroblasts. J Am Coll Cardiol 38: 2055-2062, 2001.

16. Han H, Long H, Nattel S and Wang Z: Oxidative preconditioning and apoptosis in L-cells: roles of protein kinase B and mitogen activated protein kinases. J Biol Chem 276: 26357-26364, 2001.

17. Jagtap P and Szabó C: Poly(ADP-ribose) polymerase and the therapeutic effects of its inhibitors. Nat Rev Drug Discov 4: 421-440, 2005

18. Faro R, Toyoda Y, McCully JD, et al: Myocardial protection by PJ34, a novel potent poly (ADP-ribose) synthetase inhibitor. Ann Thorac Surg 73: 575-581, 2002.

19. Szabó G, Bährle S, Stumpf N, et al: Poly(ADP-Ribose) polymerase inhibition reduces reperfusion injury after heart transplantation. Circ Res 90: 100-106, 2002.

20. Han H, Long H, Wang H, Wang J, Zhang Y and Wang Z: Progressive apoptotic cell death triggered by transient oxidative insult in H9c2 rat ventricular cells: a novel pattern of apoptosis and the mechanisms. Am J Physiol Heart Circ Physiol 286 2169-2182, 2004.
21. Gao X, Xu X, Pang J, et al: NMDA receptor activation induces mitochondrial dysfunction, oxidative stress and apoptosis in cultured neonatal rat cardiomyocytes. Physiol Res 56: 559-569, 2007.

22. Szabó C: Mechanisms of cell necrosis. Crit Care Med 33: S530-S534, 2005.

23. Murphy E and Steenbergen C: Mechanisms underlying acute protection from cardiac ischemia-reperfusion injury. Physiol Rev 88: 581-609, 2008.

24. Latyshko NV, Gudkova L, Gudkova O and Mykhailovsky V: Molecular mechanisms of catalase action under cold stress conditions. Annales SSklodowska University Press, Lublin 19: 1-32, 2006.

25. Yu N, Atienza JM Bernard J, et al: Real-time monitoring of morphological changes in living cells by electronic cell sensor arrays: an approach to study $\mathrm{G}$ protein-coupled receptors. Anal Chem 78: 35-43, 2006.

26. Ke Y, Zhang EE, Hagihara K, et al: Deletion of Shp2 in the brain leads to defective proliferation and differentiation in neural stem cells and early postnatal lethality. Mol Cell Biol 27: 6706-6717, 2007.

27. Joko T, Nanba D, Shiba F, Miyata K, Shiraishi A, Ohashi Y and Higashiyama S: Effects of promyelocytic leukemia zinc finger protein on the proliferation of cultured human corneal endothelial cells. Mol Vis 13: 649-658, 2007.

28. Vistejnova L, Dvorakova J, Hasova M, Muthny T, Velebny V, Soucek K and Kubala L: The comparison of impedance-based method of cell proliferation monitoring with commonly used metabolic-based techniques. Neuro Endocrinol Lett 30 (Suppl): 121-127, 2009 